\title{
Sclerosing peritonitis presenting as complete mechanical bowel obstruction: a case report
}

\author{
Sabah Uddin Saqib* and Inam Pal
}

\begin{abstract}
Introduction: Sclerosing peritonitis or abdominal cocoon syndrome is characterized by small bowel loops completely encapsulated by a fibrocollagenous membrane in the center of the abdomen. Although cocooning of the abdomen is mostly seen in patients on peritoneal dialysis, it can occur de novo; it very rarely manifests as complete mechanical bowel obstruction.

Case presentation: A 46-year-old Asian man presented with complete mechanical bowel obstruction. He had previous attacks of partial bowel obstruction during the past 6 to 8 months, which was misdiagnosed as abdominal tuberculosis because tuberculosis is very prevalent in the region in which he lives. He took anti-tuberculosis therapy for 3 months but this did not result in resolution of his symptoms. This time he had diagnostic laparoscopy followed by laparotomy in which a fibrocollagenous membrane, resulting in entrapment of his bowel, was excised and his entire small bowel was freed.

Postoperatively he again had a mild episode of partial bowel obstruction but this was relieved with a short course of steroids.

Discussion: Sclerosing peritonitis is a rare benign etiology of complete mechanical bowel obstruction. Patients might have suffered recurrent attacks of partial bowel obstruction in the past that were falsely managed on lines of other conditions such as tuberculosis, especially in endemic areas like Pakistan or India.

Conclusion: Sclerosing peritonitis is a rare benign diagnosis which can manifest as complete bowel obstruction and a high index of suspicion is required to diagnose it. Contrast-enhanced computed tomography of the abdomen is a useful radiological tool to aid in preoperative diagnosis. Diagnostic laparoscopy is usually confirmatory.

Peritoneal sac excision and adhesiolysis is the treatment and a short course of steroids in relapsing symptoms.
\end{abstract}

Keywords: Complete mechanical bowel obstruction, Sclerosing peritonitis, Abdominal cocoon syndrome

\section{Introduction}

Abdominal cocoon syndrome or sclerosing peritonitis is a rare condition that refers to total or partial encapsulation of the small bowel by a fibrocollagenous membrane resulting in partial or complete mechanical bowel obstruction [1]. The condition is mostly seen in patients with end-stage renal failure requiring peritoneal dialysis (PD) but it can occur without any pre-existing risk factor [2]. We report a case of an adult patient who presented

\footnotetext{
* Correspondence: Sabah.saqib@aku.edu; drsabahsaqib@hotmail.com Department of General surgery, Aga Khan University Hospital, Karachi, Pakistan
}

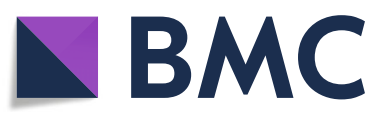

(c) The Author(s). 2019 Open Access This article is distributed under the terms of the Creative Commons Attribution 4.0 International License (http://creativecommons.org/licenses/by/4.0/), which permits unrestricted use, distribution, and reproduction in any medium, provided you give appropriate credit to the original author(s) and the source, provide a link to the Creative Commons license, and indicate if changes were made. The Creative Commons Public Domain Dedication waiver (http://creativecommons.org/publicdomain/zero/1.0/) applies to the data made available in this article, unless otherwise stated.

\section{Case presentation}

A 46-year-old Asian man presented with 5-day history of absolute constipation, vomiting, and central abdominal pain. Besides that he had no known comorbidities and an unremarkable family history. In the past he had similar complaints for which he was managed conservatively. At 4 
months prior to his presentation he had a computed tomography $(\mathrm{CT})$ scan of his abdomen for similar symptoms; the CT scan showed ileal thickening for which he was given empirically a 3-month course of anti-tuberculosis therapy (ATT) but his symptoms did not resolve.

On this occasion, an examination revealed a dehydrated patient with pulse of 104 beats/minute and blood pressure (BP) of $130 / 70 \mathrm{~mm}$. He had abdominal distention and central abdomen tenderness and hyperactive gut sounds. A digital rectal examination was unremarkable and so was a systemic examination. His baseline workup showed blood urea nitrogen of $32 \mathrm{mg} / \mathrm{dl}$ and creatinine of $1.2 \mathrm{mg} / \mathrm{dl}$.

Contrast-enhanced CT (CECT) of his abdomen showed mildly dilated thickened jejunal and ileal loops which were encased in a thick fibrocollagenous membrane pushed in the center of his abdominal cavity with collapsed loops of large bowel; the findings were suggestive of sclerosing encapsulating peritonitis/abdominal cocoon (Fig. $1 \mathrm{a}, \mathrm{b}$ ).

He was initially managed conservatively with intravenously administered fluids and nasogastric tube which resulted in some relief of his symptoms and his pulse of 74 beats/minute. Because of the fact that he came from an area where tuberculosis (TB) is a highly prevalent disease and previously he was empirically treated for abdominal $\mathrm{TB}$, he underwent colonoscopy which showed normal terminal ileum, colon and rectum (Fig. 2 a, b).

His case was discussed in a multidisciplinary team, which included a radiologist, gastroenterologist, and gastroenterology surgeon, and he was planned for diagnostic laparoscopy, followed by laparotomy in case it was not abdominal TB or a malignancy requiring medical management only.

A diagnostic laparoscopy using $10 \mathrm{~mm}$ infraumbilical port in a vertical fashion, confirmed that entire small bowel was encapsulated in membrane and it was all plastered in the center of his abdomen. Hence, a decision was made for midline laparotomy, in which thickened sclerosing membrane encapsulating loops of small bowel was removed and whole small bowel was freed and run until ileocecal junction. His stomach appeared thickened while his colon appeared grossly unremarkable (Fig. 3 a, b).

Postoperatively he remained well and was discharged on fourth postoperative day, when he was tolerating an oral soft diet. However, he was again admitted on third day after his discharge with complaints of vomiting and relative constipation. He was kept nil by mouth (NPO) and on parenteral nutrition. Along with conservative management he had a short course of hydrocortisone $50 \mathrm{mg}$ thrice daily for 7 days, which was tapered off later; he responded very well and he was discharged in a stable condition on oral soft diet with normal bowel movements.

He was followed up in clinic after 10 days and he was tolerating a soft diet with normal bowel movements; his stitches were removed in clinic. Later, a histopathology report showed fibrocollagenous tissue with mild chronic inflammation and mild patchy increase in IgG4-positive plasma cells.

He was seen twice as an out-patient at 3-month intervals and appeared asymptomatic; he was advised to have further follow-up only if required.

\section{Discussion}

Sclerosing encapsulating peritonitis was first described more than a century ago and was initially termed peritonitis chronica fibrosa incapsulata to describe the membrane encasing the intestine; it has since also been named 'icing sugar', fibroplastic peritonitis, and cocoon abdomen. Sclerosing encapsulating peritonitis has been classified as primary and secondary based on whether it is idiopathic or has a definite cause.

The etiology of the primary form is uncertain with various hypothesis, although it is probably caused by a subclinical peritonitis leading to the formation of a cocoon [3-5]. Cytokines and fibroblasts probably influence the development of peritoneal fibrosis and neoangiogenesis in some way [6].
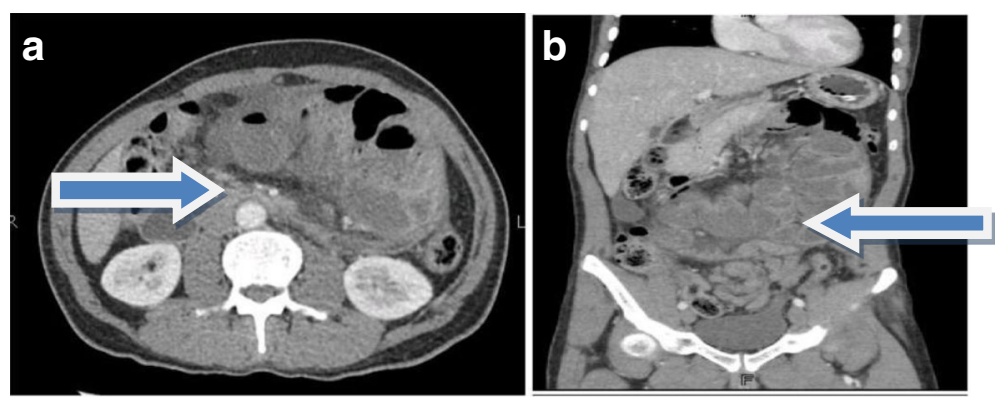

Fig. 1 a, b Axial and coronal views of contrast-enhanced computed tomography demonstrates cocooning of abdomen shown by arrows 

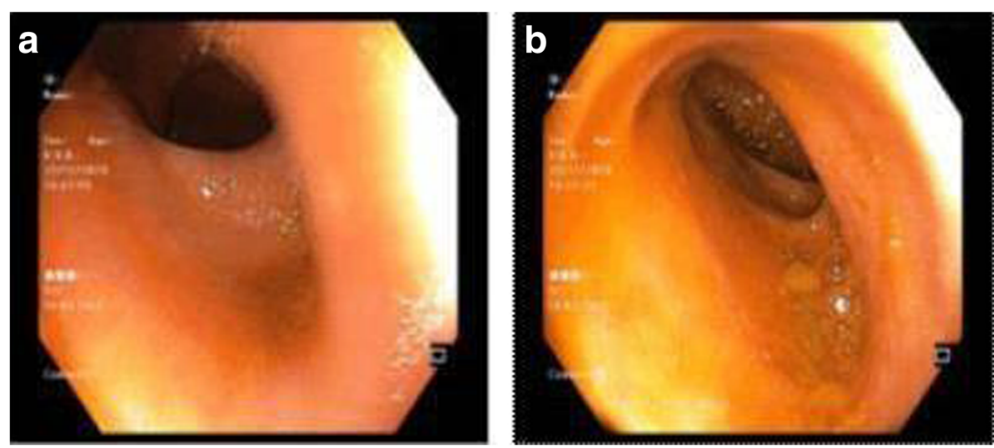

Fig. 2 a, b Normal terminal ileum on colonoscopy

Secondary sclerosing peritonitis, which is more common, has many causes. The predominant cause of sclerosing peritonitis is PD. Patients on PD are predisposed to developing peritoneal deterioration after prolonged exposure to PD fluids and subsequent bacterial peritonitis $[7,8]$. Other known causes include: recurrent peritonitis; abdominal TB; autoimmune diseases such as systemic lupus erythematosus, peritoneal shunts, and sarcoidosis; and ovarian disorders such as rupture of dermoid cyst.

The results of baseline investigations are often similar to those found in small bowel obstruction, such as dehydration and decrease in oral intake, and there may be electrolytes imbalance and acute kidney injury with raised creatinine. Abdominal X-ray findings are non-specific. CECT is a useful tool for preoperative diagnosis of abdominal cocoon $[9,10]$. The imaging features are, however, not pathognomonic. CT findings of a membrane enveloping loops of small bowel were seen in some paraduodenal hernias, abdominal cocoon, and in peritoneal encapsulation. However, the clinical and pathological features of these entities are different.

Diagnostic laparoscopy is generally confirmatory and rules out other causes [11, 12]; however, laparoscopy is not helpful in management of this condition.
Differential diagnosis includes peritoneal encapsulation, which was described as a developmental anomaly where the whole of the small bowel is encased in a thin accessory membrane. The clinical symptoms of this condition differ from those of abdominal cocoon syndrome, in that the patients are mostly asymptomatic and the findings are incidental and late in life.

Treatment, as in this case, is excision of membrane and releasing loops of bowel $[7,13]$. Bowel resection is generally not required. However, there is scarce mention in the literature of patients who relapse with symptoms after excision of membrane. As in our case, a short course of steroids may be helpful in relapsing cases because of the inflammatory nature of this condition; however, evidence of use of steroids in cases of sclerosing peritonitis needs to be established.

\section{Conclusion}

Sclerosing peritonitis is one of the rare causes of complete mechanical bowel obstruction and it should be in the differential diagnosis when no other obvious cause of bowel obstruction is found. Surgical exploration in which dense sclerosing membrane over the bowel is removed and bowel is straightened is the treatment of choice up until now. A short course of steroids is also helpful in the postoperative period.

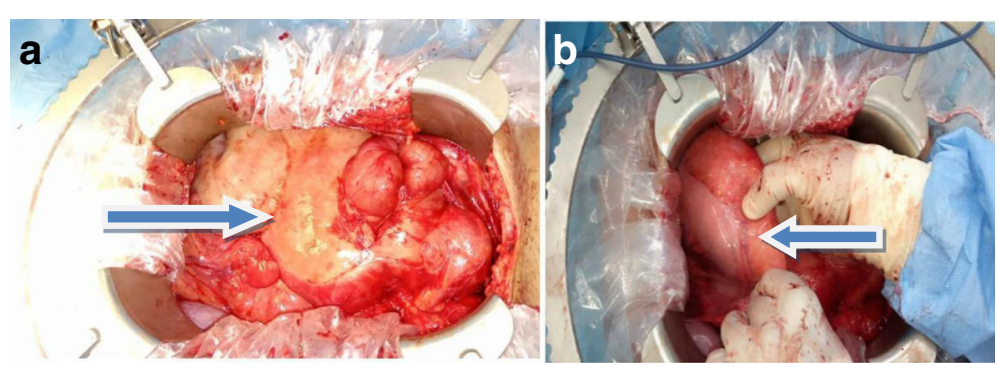

Fig. 3 a Whole small bowel is encapsulated in a membrane, shown by arrow. b Thick stomach, shown by arrow 


\section{Acknowledgements}

Ibrahim Chapra for pictures of patient; Dawar Khan for providing CT scan details and images.

\section{Authors' contributions}

SBUQ in study design, data collection, seeking consent and its approval, and writing main manuscript. IPAL, primary attending surgeon and in proofreading of this article. Both authors read and approved the final manuscript.

\section{Funding}

There is no funding body in writing this case report.

\section{Availability of data and materials}

All data will be available on request, keeping anonymity of patient.

\section{Ethics approval and consent to participate}

Informed consent from patient and exemption from Hospital review committee was sought.

\section{Consent for publication}

Written informed consent was obtained from the patient for publication of this case report and any accompanying images. A copy of the written consent is available for review by the Editor-in-Chief of this journal.

\section{Competing interests}

The authors declare that they have no competing interests.

Received: 6 May 2019 Accepted: 26 August 2019

Published online: 17 October 2019

\section{References}

1. Machado NO. Sclerosing Encapsulating Peritonitis: Review. Sultan Qaboos Univ Med J. 2016;16(2):e142-51.

2. $\quad \mathrm{Xu}$ P, Chen LH, Li YM. Idiopathic sclerosing encapsulating peritonitis (or abdominal cocoon): a report of 5 cases. World J Gastroenterol. 2007;13(26): 3649-51.

3. Tannoury JN, Abboud BN. Idiopathic sclerosing encapsulating peritonitis: abdominal cocoon. World J Gastroenterol. 2012;18(17):1999-2004.

4. Akbulut S. Accurate definition and management of idiopathic sclerosing encapsulating peritonitis. World J Gastroenterol. 2015;21(2):675-87.

5. Serter A, Kocakoc E, Cipe G. Supposed to be rare cause of intestinal obstruction; abdominal cocoon: report of two cases. Clin Imaging. 2013; 37(3):586-9.

6. Wang $\mathrm{Q}$, Wang $\mathrm{D}$. Abdominal cocoon: multi-detector row $\mathrm{CT}$ with multiplanar reformation and review of literatures. Abdom Imaging. 2010; 35(1):92-4.

7. Kawanishi H, Watanabe H, Moriishi M, Tsuchiya S. Successful surgical management of encapsulating peritoneal sclerosis. Perit Dial Int. 2005; 25(Suppl 4):S39-47.

8. Oran E, Seyit H, Besleyici C, Unsal A, Alis H. Encapsulating peritoneal sclerosis as a late complication of peritoneal dialysis. Ann Med Surg (Lond). 2015;4(3):205-7.

9. Tombak MC, Apaydin FD, Colak T, Duce MN, Balci Y, Yazici M, et al. An unusual cause of intestinal obstruction: abdominal cocoon. AJR Am J Roentgenol. 2010;194(2):W176-8.

10. Hur J, Kim KW, Park MS, Yu JS. Abdominal cocoon: preoperative diagnostic clues from radiologic imaging with pathologic correlation. AJR Am J Roentgenol. 2004;182(3):639-41.

11. Qasaimeh GR, Amarin Z, Rawshdeh BN, El-Radaideh KM. Laparoscopic diagnosis and management of an abdominal cocoon: a case report and literature review. Surg Laparosc Endosc Percutan Tech. 2010;20(5):e169-71.

12. Milone L, Gumbs A. Single incision diagnostic laparoscopy in a patient with sclerosing peritonitis. Surg Laparosc Endosc Percutan Tech. 2010;20(5):e167-8.

13. Taylor M, Clarke MG, Jarvis J, Booth M. A mystery wrapped in an enigma: the abdominal cocoon syndrome. N Z Med J. 2012;125(1366):77-80.

\section{Publisher's Note}

Springer Nature remains neutral with regard to jurisdictional claims in published maps and institutional affiliations.

Ready to submit your research? Choose BMC and benefit from:

- fast, convenient online submission

- thorough peer review by experienced researchers in your field

- rapid publication on acceptance

- support for research data, including large and complex data types

- gold Open Access which fosters wider collaboration and increased citations

- maximum visibility for your research: over $100 \mathrm{M}$ website views per year

At BMC, research is always in progress.

Learn more biomedcentral.com/submissions 